\title{
Review Article \\ Genetic Polymorphism in Extracellular Regulators of Wnt Signaling Pathway
}

\author{
Garima Sharma, ${ }^{1,2}$ Ashish Ranjan Sharma, ${ }^{1}$ Eun-Min Seo, ${ }^{1}$ and Ju-Suk Nam ${ }^{1,3}$ \\ ${ }^{1}$ Institute for Skeletal Aging \& Orthopaedic Surgery, Hallym University-Chuncheon Sacred Heart Hospital, Chuncheon-si, \\ Gangwon-do 200-704, Republic of Korea \\ ${ }^{2}$ Amity Institute of Nanotechnology, Amity University Uttar Pradesh, Noida, Uttar Pradesh 201313, India \\ ${ }^{3}$ Adbiotech Co., Ltd., Chuncheon-si, Gangwon-do 200-880, Republic of Korea \\ Correspondence should be addressed to Ju-Suk Nam; jsnam88@hallym.ac.kr
}

Received 16 January 2015; Accepted 5 March 2015

Academic Editor: Andrei Surguchov

Copyright (C) 2015 Garima Sharma et al. This is an open access article distributed under the Creative Commons Attribution License, which permits unrestricted use, distribution, and reproduction in any medium, provided the original work is properly cited.

The Wnt signaling pathway is mediated by a family of secreted glycoproteins through canonical and noncanonical mechanism. The signaling pathways are regulated by various modulators, which are classified into two classes on the basis of their interaction with either Wnt or its receptors. Secreted frizzled-related proteins (sFRPs) are the member of class that binds to Wnt protein and antagonizes Wnt signaling pathway. The other class consists of Dickkopf (DKK) proteins family that binds to Wnt receptor complex. The present review discusses the disease related association of various polymorphisms in Wnt signaling modulators. Furthermore, this review also highlights that some of the sFRPs and DKKs are unable to act as an antagonist for Wnt signaling pathway and thus their function needs to be explored more extensively.

\section{Introduction}

The Wnt family, a group of secreted glycoproteins, directs cell proliferation and polarity as well as determining the fate of a cell during embryonic development through a series of signaling transduction pathways [1]. The members of human Wnt family consist of 19 evolutionarily conserved glycoproteins having 22 or 24 cysteine residues [2]. The mechanisms followed by Wnt signaling molecules are either through canonical pathway (cell fate determination) or via noncanonical pathway (control of cell movement and tissue polarity) (Figure 1). Signal transduction during canonical Wnt pathway is mediated through the family of frizzled (FZD) receptor and low density lipoprotein related protein 5 (LRP5)/6 LRP6 coreceptors, activating $\beta$-catenin signaling cascade $[3,4]$. The Wnt signaling pathway continues after Wnt ligand binds and forms a complex with FZD and LRP6/5 together with phosphorylated scaffolding protein dishevelled (DVL). Thereafter, phosphorylation of LRP6 leads to binding of AXIN complex to the receptors, thus disabling AXIN complex to degrade $\beta$-catenin. On the contrary, the absence of Wnt ligand leads to constant degradation of cytoplasmic $\beta$-catenin protein via AXIN complex [5]. Scaffold protein AXIN and the tumor suppressor gene product adenomatous polyposis coli (APC) form AXIN complex together with casein kinase 1 (CK1) and glycogen synthase kinase 3 (GSK3). CK1 and GSK3 phosphorylate $\beta$-catenin at amino terminus followed by $\beta$-catenin recognition and ubiquitination by $\beta$-transducing repeats-containing proteins $(\beta$ $\operatorname{TrCp}$ ), an E3 ubiquitin ligase subunit directing proteasome mediated degradation [6]. As a result, $\beta$-catenin is unable to reach the nucleus and subsequently Wnt targeted genes are repressed by DNA-bound T-cell factor/lymphoid enhancer factor (TCF/LEF) family of proteins. In noncanonical signaling pathway, Wnt ligand binds to the receptors of FZD family and receptor tyrosine kinase-like orphan receptor 2/receptor tyrosine kinase (ROR2/RYK) coreceptors to form a complex. Upon stimulation by the receptors, DVL is activated leading to sequential activation of the Rho family of GTPases (small G proteins such as RhoA, RhoU, RAC, and CDC42) and JNKs. Another noncanonical Wnt signaling pathway involves activation of Wnt $/ \mathrm{Ca}^{++}$signaling cascade. 


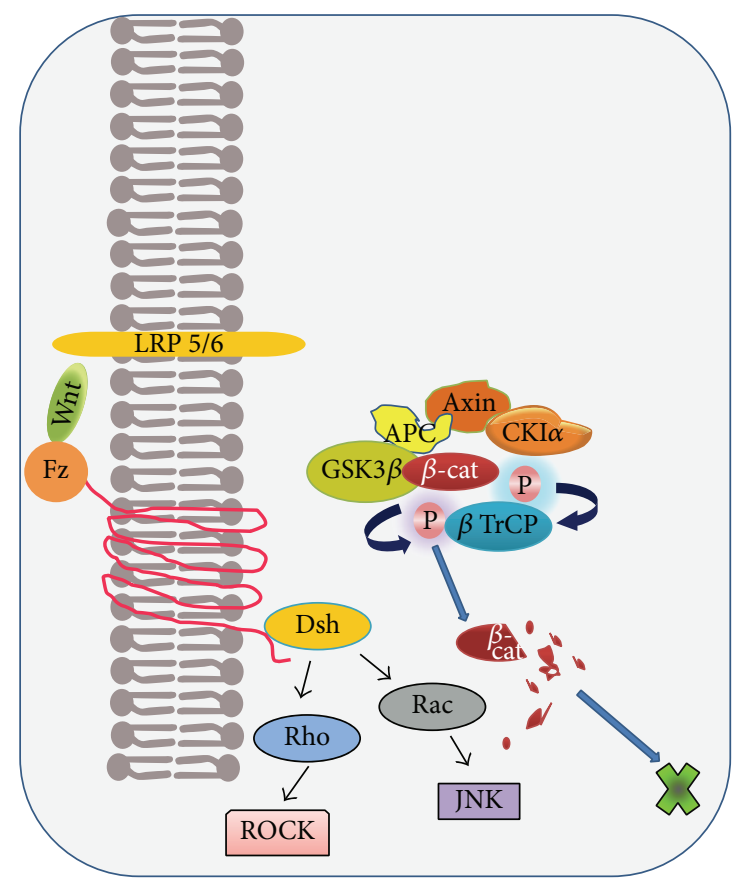

(a) Noncanonical pathway

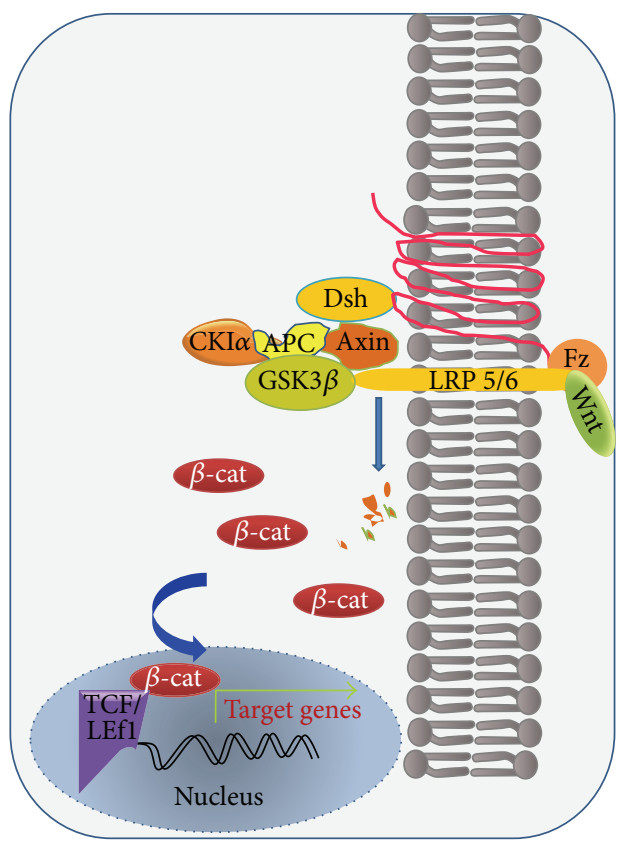

(b) Canonical pathway

FIGURE 1: Canonical and noncanonical Wnt signaling pathways.

Various natural inhibitors of Wnt signaling pathway have been identified till date, which can antagonize or regulate Wnt signaling pathway (Figure 2). The mechanism of Wnt antagonists has been highlighted by various developmental studies performed in various chick and Xenopus models $[7,8]$. Broadly, antagonists of Wnt signaling pathway are divided into two classes depending on their functional mechanism, that is, secreted frizzled-related proteins (sFRPs) and Dickkopfs (DKKs). The members of sFRP class can bind to Wnts and thus regulate the association of Wnt ligands to their transmembrane receptors, inhibiting both canonical and noncanonical signaling pathways. The sFRP class constitutes sFRP family proteins: WIF-1 and Cerberus. Another class of antagonists, that is, DKK class, binds to LRP5/LRP6 component of the Wnt receptor complex to inhibit canonical Wnt signaling and constitutes DKK family proteins and sclerostin [9]. Besides antagonists, Wnt signaling pathway is also activated and regulated by some secreted proteins acting as agonists, for example, R-spondin (Rspo) [10].

As mentioned earlier Wnt signaling is one of the most critical pathways for cellular development, even in adult tissues; henceforth, the polymorphism in genes of Wnt signaling modulators can be a foremost cause for various types of associated diseases. The present review highlights disease associated polymorphism studies in some of the Wnt signaling modulators. Summarizing the role of polymorphism in Wnt signaling modulators can open a new spectrum to understand the origin of various related diseases and to trace out novel pathways for potential therapeutics.

\section{Polymorphism in SOST/Sclerostin}

Sclerostin is a SOST gene encoded secreted glycoprotein containing cysteine knot which acts as a Wnt antagonist and regulates skeletal mineralization $[11,12]$. Recently, expression of SOST mRNA has also been reported in various cells, including liver, blood vessels, and kidneys [13], though these organs are devoid of sclerostin protein. The major expression of sclerostin protein has been found in skeletal tissues such as articular chondrocytes [14] and cementocytes [15]. Even during inflammatory diseases like periprosthetic osteolysis, it has been shown to be induced in osteoblasts by cytokines like tumor necrosis factor alpha (TNF $\alpha)$ [16]. In osteocytes and osteoblasts, sclerostin functions as a Wnt $/ \beta$-catenin signaling antagonist by binding to LRP $5 / 6$ receptors and thus inhibiting bone formation [17]. SOST genes have been associated with osteoporotic fractures and bone mineral density (BMD) [18-20]. However, in a different study, performed on 619 perimenopausal Scottish women, single nucleotide polymorphism (SNP) in SOST gene region was not found associated with high or low BMD at lumbar spine [21]. Similarly, in a genotypic study of 652 Slovenian populations BMD was not associated with -1397/-1396insGGA SOST polymorphism [22]. On the contrary, a genome wide linkage analysis of Chinese cohort revealed that the genetic polymorphism in sclerostin domain-containing protein 1 (SOSTDC1) has correlation with bone mass density [23]. Although difference between SOST genotype in correspondence to the allele dose effect was also observed concluding the necessity for large 


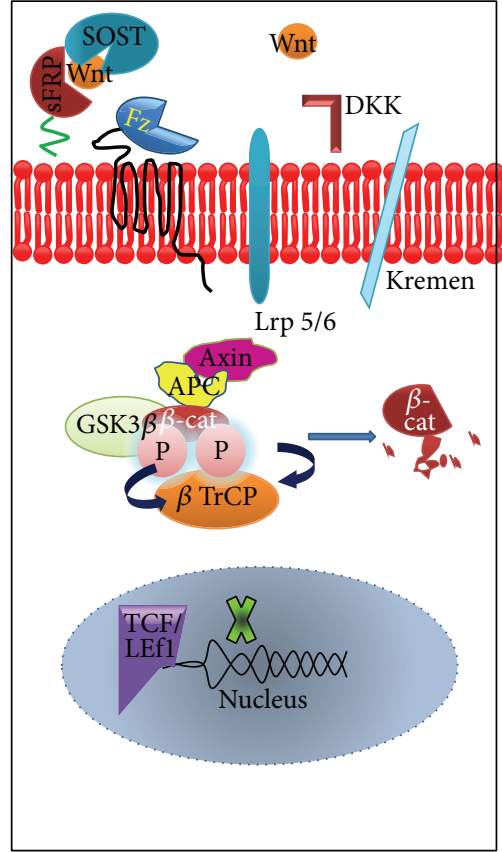

(a) No Wnt

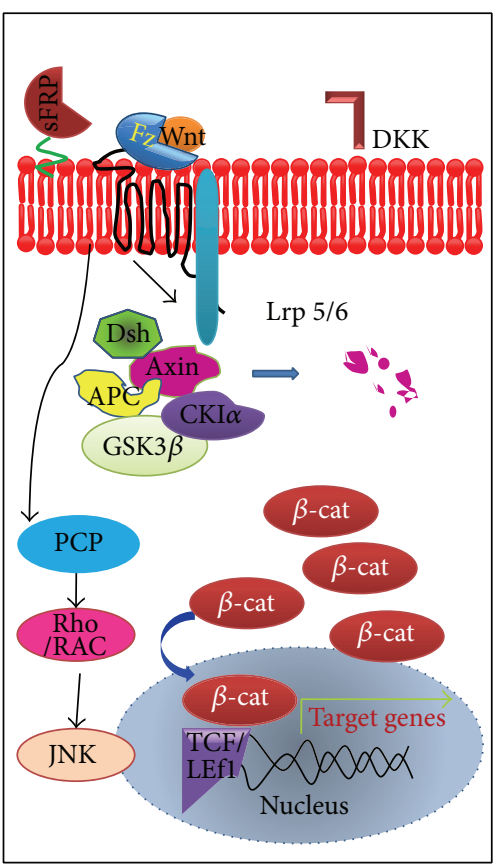

(b) Wnt binding

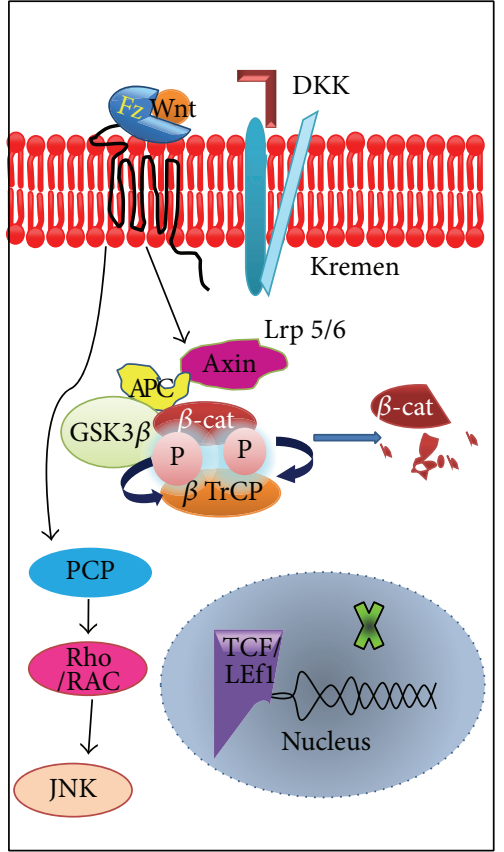

(c) Wnt with DKK

FIGURE 2: Role of antagonists in Wnt signaling pathway.

sample size, Li et al., 2008, showed increases in BMD in SOST knockout mice [24]. It has been earlier reported that loss of function mutations in the SOST gene leads to monogenic bone disorder, sclerosteosis (Online Mendelian Inheritance in Man ID: 269500), characterized by hyperostosis all over the skeleton (massive bone overgrowth) [25, 26]. Additionally, another mutation ( $52 \mathrm{~kb}$ deletion) at $35 \mathrm{~kb}$ downstream of the SOST gene causes van Buchem disease with similar disease phenotype [27, 28]. Uitterlinden et al., 2004 [29], hypothesized that polymorphism in SOST gene region influences the function of sclerostin causing variations in BMD in a subset of the population. Further, to verify their hypothesis they observed eight polymorphisms within the region of the SOST gene, which were in relation to BMD observed in 1,939 elderly Dutch white. According to their results, a decrease in BMD of spine/femoral neck in Dutch white females was associated with a $3 \mathrm{bp}$ insertion in the SOST promoter region (SOST gene region polymorphism 3 ) and increase in BMD of spine/femoral neck in Dutch white males was associated with G variant of SOST-region polymorphism 9, that is, van Buchem deletion region. Recently, two BMD associated SNPs (rs851054 and rs851056) were also identified in $5^{\prime}$ region of SOST gene [18]. Styrkarsdottir et al., 2009, also identified three SNPs that were in association with BMD and were located at $3^{\prime}$ SOST gene region between $23 \mathrm{~kb}$ and $57 \mathrm{~kb}$ (rs1513670, rs7220711, and rs1107748) [30]. Evidence of association between BMD and -9247 polymorphism (rs1230399) at $5^{\prime}$ SOST gene region was also proved by a gene wide tag SNP association study performed on Chinese population (1243 subjects) with low and high BMD [31].

\section{Polymorphism in Secreted Frizzled Related Protein (sFRP)}

Based on sequence homology, the five members of sFRP family (sFRP1 to sFRP5) are divided into two subgroups. sFRP1, sFRP2, and sFRP5 constitute one subgroup while sFRP3 and sFRP4 are in another subgroup. These proteins are soluble cysteine rich and bind directly to Wnt molecules antagonizing Wnt signaling pathway [38]. sFRP3, also known as FrzB, was the first purified chondrogenic factor from cartilage [39]. Conflicting roles of sFRPs have recently been reported, such as sFRP1 that acts as an agonist, in vitro, at low concentration [40] while sFRP1 promotes angiogenesis in a chick chorioallantoic membrane model [41]. The role of SFRP3 in the etiology of osteoarthritis has been discussed in many reports. Replication studies among Caucasian women showed two SNPs in $s F R P 3 / F r z B$ gene, R200W (rs288326) and R324G (rs7775), may elevate knee osteoarthritis [32]. In another SNP analysis, association of these haplotypes with hip osteoarthritis have also been shown in a large population of postmenopausal Caucasian women [33]. In addition, the authors considered the contribution of SNPs and suggested them as a biomarker for osteoarthritis. Transfection studies in human embryonic kidney 293 cells (HEK293), performed by Loughlin et al., 2004, [42] displayed that substitution of highly conserved positively charged arginine residues reduces the antagonizing ability of sFRP3/FrzB. sFRP3, as expressed by chondrocytes, mediated inhibition of Wnt signaling pathway is known to be vital for maintaining the integrity of cartilage-bone junction. Therefore, R324G 
SNP in $s F R P 3$ results in structurally occult hip dysplasia leading to osteoarthritis. Further, they revealed that the G allele of R324G variant is in close association with hip replacement in elderly females. Furthermore, Min et al., 2005, also showed increased incidence of G allele of this variant in individuals with hip radiographic osteoarthritis. According to them individuals as $G$ allele carrier have a high risk for hip radiographic osteoarthritis [43]. Similar results were also observed in a study performed in Spanish cohort observing association between FRZB and hip, knee, and hand osteoarthritis. Group observed increased frequency of R324G in patients with multiple joint osteoarthritis and in females with hip osteoarthritis [34]. Besides osteoarthritis, rs7775 SNP in $s F R P$ gene has been shown to exhibit a strong association with breast cancer. SNP rs7775 was found in exon 6 and was observed to encode arginine (CGC) or glycine (GGC) in Saudi women [35].

\section{Polymorphism in Dickkopf}

Another class of Wnt antagonist is cysteine rich secreted protein known as Dickkopf (DKK-1 to -4) which binds to LRP5/6 receptor and Kremen 1/2 (transmembrane protein) and inhibits Wnt signaling pathway. In human the gene for DKK-1 is located in 10q11.2 position of chromosome (NM_012242.2). As a result, the canonical pathway of Wnt signaling is inhibited $[44,45]$. Studies in human DKK-1 showed a multifaceted effect on proliferation and differentiation of various cells like human adult bone marrow cells [46], adipocytes [47], and osteoblasts [48]. Moreover, the elevation of the DKK-1 level by glucocorticoids in osteoblasts that may lead to osteoporosis has also been observed [49]. In addition, Tian et al., 2003, observed the association of lytic bone lesions and elevated DKK-1 level in patients with multiple myeloma [50]. Reports suggest that the induction of DKK-1 is dependent on p53 and thus DKK1 acting as Wnt antagonist may lead to p53 tumor suppression [51]. Shou et al., 2002, also suggested the proapoptotic role of DKK1 which links oncogenic Wnt and p53 tumor suppressor pathways [52]. Various reports showed antitumor effect of DKK-1 on different cell lines like HeLa cervical cancer cells $[53,54]$, colon cancer cells $[55,56]$, breast cancer cells $[57,58]$, renal cancer cells [59], and so forth.

Ralston et al. [60] suggested the association of DKK-1 gene containing chromosomal region 10q21 with BMD in men through genome wide linkage scan. The influence of genetic variation in DKK-1 on hip geometry, BMD, and bone turnover has been studied earlier by Piters et al., 2010 [36]. They selected three SNPs (rs2241529 (G/A), rs1569198 (A/G), and rs1991392 (A/C)) using HapMap within $13.53 \mathrm{~kb}$ DKK-1 region and studied a group of 783 Caucasian men of 20-29 years. According to them, rs1569198 had significant association with hip axis length (HAL) and was independent of BMD and height. Results observed were further confirmed by haplotype analysis indicating increased risk of hip fracture in the general population. However, they further concluded that all the variants do not influence BMD or bone turnover marker, in chosen subjects, which was later on supported by other reports [61]. For the first time, the association of SNP rs6485350 in DKK-3 gene and rs3763511 in DKK-4 with breast cancer risk was studied by Alanazi et al., 2013 [35]. Study reported 2-fold reduced breast cancer risk in women with GG genotype as compared to AA genotype in case of DKK3 gene SNP. Furthermore, GG genotype and AG genotype showed enhanced protection against estrogen receptor positive tumor and estrogen receptor negative tumor progression, respectively. Conversely, SNP in DKK-4 gene was strongly associated with age independent increased breast cancer risk of estrogen receptor negative tumor. In order to determine the relationship between polymorphism in $D K K$ genes and renal cancer Hirata et al., 2009 [37], examined 210 renal cancer positive patients (145 male and 65 female). Through PCRRFLP and direct sequencing genotype of SNP rs17037102 and rs419559, rs447372 in DKK-2, rs3206824, rs11022095, rs1472189, rs7396187, and rs2291599 in DKK-3, and rs2073664 in $D K K-4$ were analyzed. Results demonstrated significant association of $D K K-3 \mathrm{rs} 1472189 \mathrm{C} / \mathrm{T}$ with renal cell carcinoma and SNP rs17037102 G DKK-2 may contribute to increased survival rate in patients, after radical nephrectomy.

\section{Wnt Inhibitory Factor 1}

Another evolutionary conserved modulator protein of Wnt signaling is Wnt inhibitory factor 1 (Wif 1). It is similar to sFRPs and inhibits Wnt signaling by binding to Wnt proteins. Wif 1 contains epidermal growth factor like repeats (EGF repeats) and Wif domain which binds to Wnt proteins [62, 63]. As reported, Wif 1 is responsible for tumor suppression and epigenetic silencing and may lead to increased risk of cancer by modulating Wnt signaling pathway. Studies showed increased Wif 1 expression in C2C12, MC3T3-E1, and KS483 cells during BMP-2 induced osteoblasts differentiation suggesting the role of Wif 1 as modulator of osteoblasts differentiation and maturation [64]. Various studies have demonstrated that tumorigenesis gene silencing can be a result of abnormal methylation in promoter region of tumor suppressor genes [65, 66]. Kawakami et al., 2009, reported the downregulation of Wif 1 by promoter hypermethylation in renal cancer cells [67]. In addition, hypermethylation of Wif 1 gene promoter region was found to downregulate Wif 1 gene in prostate cancer cell lines. Further, a decreased motility and invasiveness of prostate cancer cells were reported after restoration of Wif 1 expression [68]. Correlation of the reduced Wif 1 expression due to Wif 1 promoter hypermethylation and increase in bladder tumor has also been reported by other research groups $[69,70]$. Wif 1 gene has also been reported to be involved in osteosarcoma. Study performed by Kansara et al. revealed that in primary human osteosarcoma promoter hypermethylation leads to Wif 1 gene silencing, which results in loss of differentiation and increased cell proliferation [71]. Taking into account the importance of Wif gene in regulation of tumorigenesis and any probability of existence of polymorphism in Wif gene, which may result in deleterious effect, makes it a probable candidate for requiring urgent studies for verifying its role in regulation of Wnt signaling pathway. 
TABLE 1: SNPs in the selected genes and associated clinical phenotypes.

\begin{tabular}{|c|c|c|c|c|c|}
\hline Gene & Chromosome & SNP ID & Geographical cohort & Phenotype & Reference \\
\hline $\begin{array}{l}\text { SOST } \\
\text { DC1 }\end{array}$ & $7 \mathrm{p} 21.1$ & $\begin{array}{r}\text { rs16878759 } \\
\text { rs12699800 } \\
\text { rs17619769 }\end{array}$ & China & Osteoporosis & {$[23]$} \\
\hline SOST & $17 q 21.3$ & $\begin{array}{l}\mathrm{rs} 851054 \\
\mathrm{rs} 851056\end{array}$ & Australia & $\mathrm{BMD}$ and $\mathrm{BMC}$ at total hip & {$[18]$} \\
\hline SOST & $17 \mathrm{q} 21.3$ & $\begin{array}{l}\text { rs1513670 } \\
\text { rs7220711 } \\
\text { rs1107748 }\end{array}$ & Iceland, Denmark, and Australia & Hip BMD associated & {$[30]$} \\
\hline SOST & $17 \mathrm{q} 21.3$ & rs1230399 & China & $\begin{array}{l}\text { Spine, FN, trochanter, and } \\
\text { total hip BMD }\end{array}$ & {$[31]$} \\
\hline sFRP3 & $2 \mathrm{q} 32.1$ & $\begin{array}{l}\text { rs288326 } \\
\text { rs7775 }\end{array}$ & Caucasian, Spanish & $\begin{array}{c}\text { Knee osteoarthritis, hip } \\
\text { osteoarthritis }\end{array}$ & [32-34] \\
\hline$s F R P 3$ & $2 \mathrm{q} 32.1$ & rs7775 & Saudi & Breast cancer & [35] \\
\hline$D K K 1$ & $10 \mathrm{q} 21$ & rs1569198 & Caucasian & Hip axis length & {$[36]$} \\
\hline DKK3 & $11 \mathrm{p} 15.3$ & rs6485350 & Saudi & Breast cancer & {$[35]$} \\
\hline DKK3 & $11 \mathrm{p} 15.3$ & rs1472189 & Japan & Renal cancer & {$[37]$} \\
\hline DKK4 & 8p11.1 & rs3763511 & Saudi & Breast cancer & {$[35]$} \\
\hline
\end{tabular}

\section{R-Spondins}

R-spondins are a newly discovered, cysteine rich and containing a thrombospondin type 1 domain/repeat-1, secreted protein family consisting of 4 members (Rspol-4). Recently, Rspo has been reported to act as modulators of Wnt signaling pathway. Rspo has been demonstrated to upregulate the Wnt signaling pathway by stabilizing cytosolic $\beta$-catenin $[72,73]$. This is achieved by the binding of Rspo to LRP6 and thus disrupting LRP6-DKK complex, which further enhances the deactivation of canonical Wnt signaling $[10,74]$. All the members of Rspo family have common structural organization and share around $60 \%$ sequence homology [75]. Recently, few studies reported that Rspo modulates Wnt signaling pathway through $G$ protein-coupled receptors called leucine-rich repeat-containing $\mathrm{G}$ protein-coupled receptor (LGR) [76, 77]. Till date, three types of LGRs (LGR4-6) have been identified. As 7 transmembrane receptors, LGRs consist of leucine-rich repeats at extracellular $\mathrm{N}$-terminal domain and are capable of binding to all four Rspo proteins [78]. Studies suggested that LRP/Wnt/Fz complex interacts with LRG-Rspo complex [79, 80]. Although the functional mechanism of Rspo mediated Wnt signaling has been discussed in some reports, yet, the exact mechanism of action for Rspo still remains to be elucidated. The association of Rspo family and bone metabolism has been documented in some studies, signified by the high level of Rspo protein expression in skeletal tissues at developmental stages and lacking of Rspo resulting in defected skeletal formation [81, 82]. Lately, mutations in Rspo4 have been reported and were found associated with the absence of finger and toe nails (autosomal recessive anonychia/hyponychia) (OMIM 206800) in humans [83-86]. Khan et al., 2012, identified mutations (c.178C>T (p.R60W), c.353G>A (p.C118Y), and c.3G $>$ A (p.M1I)) within chromosome 20p13 at Rspo4 locus after genotyping three anonychia/hyponychia Pakistani families using microsatellite markers. Study expanded RSPO4 mutations related with anonychia/hyponychia to 17 and all of them were found located in the first three exons encoding a signal peptide and the highly conserved furin-like cysteinerich domains. Study concluded and suggested that p.M1I variant is a recurrent mutation among Pakistani patients and can be considered as a polymorphism, having no effect on the observed disorder [87].

\section{Conclusion and Perspectives}

The functional complexity of Wnt signaling pathway has driven the interest of leading researchers towards in-depth analysis of Wnt signaling controlling factors. The extracellular antagonists and agonists provide defined regulation of signal and their further transmission. Herein, we have tried to summarize the various reported polymorphisms in known antagonists (sFRP, DKK, and Wif-1) and agonists (Rspo) of Wnt signaling pathway leading to the observed diseased state in humans (Table 1). As discussed in above sections both antagonists and agonists possess polymorphisms and have been linked to deleterious effects on human health. Therefore, the detailed genetic study of these antagonists and agonists may serve as a useful tool for understanding the development and progression of various diseases. Furthermore, genetic identification of Wnt signaling antagonists, responsible for disease susceptibility, remains at priority attention for cell biologists. Although extensive work has been carried out in recent years, nevertheless, we still need to understand the association of polymorphism in genes of antagonists and the progression of diseases. Advancements in this area may provide an insight and tend to open new opportunities for the early identification and treatments for yet incurable diseases.

\section{Abbreviations}

LRP 5/6: Low density lipoprotein receptor-related protein 5/6 
Fz: $\quad$ Frizzled receptor protein

GSK3 $\beta$ : Glycogen synthase kinase 3 beta

APC: $\quad$ Adenomatosis polyposis coli protein

CKI $\alpha$ : $\quad$ Cyclin-dependent kinase inhibitor alpha

$\beta$ TrCp: $\quad$ Beta-transducin repeat containing E3 ubiquitin protein ligase

WNT: Wingless-type MMTV integration site protein family

TCF/LEf1: T-cell factor/lymphoid-enhancing factor type 1

DVL: Dishevelled protein

Rho: Ras-like proteins

ROCK: Rho-associated kinase

ROR2: Receptor tyrosine kinase-like orphan receptor 2

JNKs: c-Jun N-terminal kinases

DKK: Dickkopf

sFRP: $\quad$ Secreted frizzled-related protein

Kremen: Kringle containing transmembrane protein

Wif: Wnt inhibitory factor

Rspo: R-spondin

LGR: $\quad$ Leucine-rich repeat-containing, G protein-coupled receptor

OMIM: Online mendelian inheritance in man.

\section{Conflict of Interests}

The authors declare that they do not have a conflict of interests for any of the organizations or authors that might have influenced the performance or presentation of the work described in this paper.

\section{Acknowledgment}

This research was supported by the Basic Science Research Program through the National Research Foundation of Korea (NRF), funded by the Ministry of Education (2014R1A1A2055560).

\section{References}

[1] C. Y. Logan and R. Nusse, "The Wnt signaling pathway in development and disease," Annual Review of Cell and Developmental Biology, vol. 20, pp. 781-810, 2004.

[2] M. Katoh, "WNT and FGF gene clusters (review)," International Journal of Oncology, vol. 21, no. 6, pp. 1269-1273, 2002.

[3] P. Bhanot, M. Brink, C. H. Samos et al., "A new member of the frizzled family from Drosophila functions as a wingless receptor," Nature, vol. 382, no. 6588, pp. 225-231, 1996.

[4] K. I. Pinson, J. Brennan, S. Monkley, B. J. Avery, and W. C. Skarnes, "An LDL-receptor-related protein mediates Wnt signalling in mice," Nature, vol. 407, no. 6803, pp. 535-538, 2000.

[5] A. Kikuchi, H. Yamamoto, and A. Sato, "Selective activation mechanisms of Wnt signaling pathways," Trends in Cell Biology, vol. 19, no. 3, pp. 119-129, 2009.

[6] X. He, M. Semenov, K. Tamai, and X. Zeng, "LDL receptorrelated proteins 5 and 6 in Wnt/ $\beta$-catenin signaling: arrows point the way," Development, vol. 131, no. 8, pp. 1663-1677, 2004.
[7] C. Niehrs, O. Kazanskaya, W. Wu, and A. Glinka, "Dickkopf1 and the Spemann-Mangold head organizer," International Journal of Developmental Biology, vol. 45, no. 1, pp. 237-240, 2001.

[8] T. P. Yamaguchi, "Heads or tails: Wnts and anterior-posterior patterning," Current Biology, vol. 11, no. 17, pp. R713-R724, 2001.

[9] C. Beyer and G. Schett, "Novel targets in bone and cartilage," Best Practice and Research: Clinical Rheumatology, vol. 24, no. 4, pp. 489-496, 2010.

[10] K.-A. Kim, M. Wagle, K. Tran et al., "R-Spondin family members regulate the Wnt pathway by a common mechanism," Molecular Biology of the Cell, vol. 19, no. 6, pp. 2588-2596, 2008.

[11] X. Li, Y. Zhang, H. Kang et al., "Sclerostin binds to LRP5/6 and antagonizes canonical Wnt signaling," The Journal of Biological Chemistry, vol. 280, no. 20, pp. 19883-19887, 2005.

[12] D. G. Monroe, M. E. McGee-Lawrence, M. J. Oursler, and J. J. Westendorf, "Update on Wnt signaling in bone cell biology and bone disease," Gene, vol. 492, no. 1, pp. 1-18, 2012.

[13] M. J. C. Moester, S. E. Papapoulos, C. W. G. M. Löwik, and R. L. van Bezooijen, "Sclerostin: current knowledge and future perspectives," Calcified Tissue International, vol. 87, no. 2, pp. 99-107, 2010.

[14] B. Y. Chan, E. S. Fuller, A. K. Russell et al., "Increased chondrocyte sclerostin may protect against cartilage degradation in osteoarthritis," Osteoarthritis and Cartilage, vol. 19, no. 7, pp. 874-885, 2011.

[15] A. Jäger, W. Götz, S. Lossdörfer, and B. Rath-Deschner, "Localization of SOST/sclerostin in cementocytes in vivo and in mineralizing periodontal ligament cells in vitro," Journal of Periodontal Research, vol. 45, no. 2, pp. 246-254, 2010.

[16] S.-S. Lee, A. R. Sharma, B.-S. Choi et al., "The effect of TNFalpha; secreted from macrophages activated by titanium particles on osteogenic activity regulated by WNT/BMP signaling in osteoprogenitor cells," Biomaterials, vol. 33, no. 17, pp. 42514263, 2012.

[17] M. Semënov, K. Tamai, and X. He, "SOST is a ligand for LRP5/LRP6 and a Wnt signaling inhibitor," Journal of Biological Chemistry, vol. 280, no. 29, pp. 26770-26775, 2005.

[18] A.-M. Sims, N. Shephard, K. Carter et al., "Genetic analyses in a sample of individuals with high or low BMD shows association with multiple Wnt pathway genes," Journal of Bone and Mineral Research, vol. 23, no. 4, pp. 499-506, 2008.

[19] J.-M. Liu, M.-J. Zhang, L. Zhao et al., "Analysis of recently identified osteoporosis susceptibility genes in Han Chinese women," Journal of Clinical Endocrinology and Metabolism, vol. 95, no. 9, pp. E112-E120, 2010.

[20] U. Styrkarsdottir, B. V. Halldorsson, D. F. Gudbjartsson et al., "European bone mineral density loci are also associated with BMD in East-Asian populations," PLoS ONE, vol. 5, no. 10, Article ID e13217, 2010.

[21] W. Balemans, D. Foernzler, C. Parsons et al., "Lack of association between the SOST gene and bone mineral density in perimenopausal women: analysis of five polymorphisms," Bone, vol. 31, no. 4, pp. 515-519, 2002.

[22] S. Mencej-Bedrač, J. Preželj, T. Kocjan, R. Komadina, and J. Marc, "Analysis of association of LRP5, LRP6, SOST, DKK1, and CTNNB1 genes with bone mineral density in a Slovenian population," Calcified Tissue International, vol. 85, no. 6, pp. 501-506, 2009.

[23] J.-W. He, H. Yue, W.-W. Hu, Y.-Q. Hu, and Z.-L. Zhang, "Contribution of the sclerostin domain-containing protein 1 (SOSTDC1) gene to normal variation of peak bone mineral 
density in Chinese women and men," Journal of Bone and Mineral Metabolism, vol. 29, no. 5, pp. 571-581, 2011.

[24] X. Li, M. S. Ominsky, Q.-T. Niu et al., "Targeted deletion of the sclerostin gene in mice results in increased bone formation and bone strength," Journal of Bone and Mineral Research, vol. 23, no. 6, pp. 860-869, 2008 .

[25] W. Balemans, M. Ebeling, N. Patel et al., "Increased bone density in sclerosteosis is due to the deficiency of a novel secreted protein (SOST)," Human Molecular Genetics, vol. 10, no. 5, pp. 537-543, 2001.

[26] M. E. Brunkow, J. C. Gardner, J. van Ness et al., "Bone dysplasia sclerosteosis results from loss of the SOST gene product, a novel cystine knot-containing protein," American Journal of Human Genetics, vol. 68, no. 3, pp. 577-589, 2001.

[27] W. Balemans, N. Patel, M. Ebeling et al., "Identification of a 52 $\mathrm{kb}$ deletion downstream of the SOST gene in patients with van Buchem disease," Journal of Medical Genetics, vol. 39, no. 2, pp. 91-97, 2002.

[28] K. Staehling-Hampton, S. Proll, B. W. Paeper et al., "A 52-kb deletion in the SOST-MEOX1 intergenic region on 17q12-q21 is associated with van Buchem disease in the Dutch population," American Journal of Medical Genetics, vol. 110, no. 2, pp. 144-152, 2002.

[29] A. G. Uitterlinden, P. P. Arp, B. W. Paeper et al., "Polymorphisms in the sclerosteosis/van Buchem disease gene (SOST) region are associated with bone-mineral density in elderly whites," American Journal of Human Genetics, vol. 75, no. 6, pp. 10321045, 2004.

[30] U. Styrkarsdottir, B. V. Halldorsson, S. Gretarsdottir et al., "New sequence variants associated with bone mineral density," Nature Genetics, vol. 41, no. 1, pp. 15-17, 2009.

[31] Q.-Y. Huang, G. H. Y. Li, and A. W. C. Kung, "The-9247 T/C polymorphism in the SOST upstream regulatory region that potentially affects $\mathrm{C} / \mathrm{EBP} \alpha$ and FOXA1 binding is associated with osteoporosis," Bone, vol. 45, no. 2, pp. 289-294, 2009.

[32] A. M. Valdes, J. Loughlin, M. Van Oene et al., "Sex and ethnic differences in the association of ASPN, CALM1, COL2A1, $C O M P$, and $F R Z B$ with genetic susceptibility to osteoarthritis of the knee," Arthritis and Rheumatism, vol. 56, no. 1, pp. 137-146, 2007.

[33] N. E. Lane, K. Lian, M. C. Nevitt et al., "Frizzled-related protein variants are risk factors for hip osteoarthritis," Arthritis \& Rheumatism, vol. 54, no. 4, pp. 1246-1254, 2006.

[34] J. Rodriguez-Lopez, M. Pombo-Suarez, M. Liz, J. J. GomezReino, and A. Gonzalez, "Further evidence of the role of frizzled-related protein gene polymorphisms in osteoarthritis," Annals of the Rheumatic Diseases, vol. 66, no. 8, pp. 1052-1055, 2007.

[35] M. S. Alanazi, N. R. Parine, J. P. Shaik, H. A. Alabdulkarim, S. A. Ajaj, and Z. Khan, "Association of single nucleotide polymorphisms in Wnt signaling pathway genes with breast cancer in Saudi patients," PLoS ONE, vol. 8, no. 3, Article ID e59555, 2013.

[36] E. Piters, W. Balemans, T. L. Nielsen et al., "Common genetic variation in the DKK1 gene is associated with hip axis length but not with bone mineral density and bone turnover markers in young adult men: results from the Odense Androgen Study," Calcified Tissue International, vol. 86, no. 4, pp. 271-281, 2010.

[37] H. Hirata, Y. Hinoda, K. Nakajima et al., "Wnt antagonist gene polymorphisms and renal cancer," Cancer, vol. 115, no. 19, pp. 4488-4503, 2009.
[38] B. Zhang and J.-X. Ma, "Wnt pathway antagonists and angiogenesis," Protein and Cell, vol. 1, no. 10, pp. 898-906, 2010.

[39] B. Hoang, M. Moos Jr., S. Vukicevic, and F. P. Luyten, "Primary structure and tissue distribution of FRZB, a novel protein related to Drosophila frizzled, suggest a role in skeletal morphogenesis," Journal of Biological Chemistry, vol. 271, no. 42, pp. 26131-26137, 1996.

[40] J. Hu, A. Dong, V. Fernandez-Ruiz et al., "Blockade of Wnt signaling inhibits angiogenesis and tumor growth in hepatocellular carcinoma," Cancer Research, vol. 69, no. 17, pp. 6951-6959, 2009.

[41] P. Dufourcq, T. Couffinhal, J. Ezan et al., "FrzA, a secreted frizzled related protein, induced angiogenic response," Circulation, vol. 106, no. 24, pp. 3097-3103, 2002.

[42] J. Loughlin, B. Dowling, K. Chapman et al., "Functional variants within the secreted frizzled-related protein 3 gene are associated with hip osteoarthritis in females," Proceedings of the National Academy of Sciences of the United States of America, vol. 101, no. 26, pp. 9757-9762, 2004.

[43] J. L. Min, I. Meulenbelt, N. Riyazi et al., "Association of the frizzled-related protein gene with symptomatic osteoarthritis at multiple sites," Arthritis and Rheumatism, vol. 52, no. 4, pp. 1077-1080, 2005.

[44] A. Bafico, G. Liu, A. Yaniv, A. Gazit, and S. A. Aaronson, "Novel mechanism of Wnt signalling inhibition mediated by Dickkopf1 interaction with LRP6/Arrow," Nature Cell Biology, vol. 3, no. 7, pp. 683-686, 2001.

[45] B. Mao, W. Wu, G. Davidson et al., "Kremen proteins are Dickkopf receptors that regulate Wnt/ $\beta$-catenin signalling," Nature, vol. 417, no. 6889, pp. 664-667, 2002.

[46] C. A. Gregory, H. Singh, A. S. Perry, and D. J. Prockop, “The Wnt signaling inhibitor Dickkopf-1 is required for reentry into the cell cycle of human adult stem cells from bone marrow," The Journal of Biological Chemistry, vol. 278, no. 30, pp. 2806728078, 2003.

[47] C. Christodoulides, M. Laudes, W. P. Cawthorn et al., "The Wnt antagonist Dickkopf-1 and its receptors are coordinately regulated during early human adipogenesis," Journal of Cell Science, vol. 119, no. 12, pp. 2613-2620, 2006.

[48] F. Morvan, K. Boulukos, P. Clément-Lacroix et al., "Deletion of a single allele of the Dkk1 gene leads to an increase in bone formation and bone mass," Journal of Bone and Mineral Research, vol. 21, no. 6, pp. 934-945, 2006.

[49] K. Ohnaka, H. Taniguchi, H. Kawate, H. Nawata, and R. Takayanagi, "Glucocorticoid enhances the expression of dickkopf-1 in human osteoblasts: novel mechanism of glucocorticoid-induced osteoporosis," Biochemical and Biophysical Research Communications, vol. 318, no. 1, pp. 259-264, 2004.

[50] E. Tian, F. Zhan, R. Walker et al., "The role of the Wnt-signaling antagonist DKK1 in the development of osteolytic lesions in multiple myeloma," The New England Journal of Medicine, vol. 349, no. 26, pp. 2483-2494, 2003.

[51] J. Wang, J. Shou, and X. Chen, "Dickkopf-1, an inhibitor of the Wnt signaling pathway, is induced by p53," Oncogene, vol. 19, no. 14, pp. 1843-1848, 2000.

[52] J. Shou, F. Ali-Osman, A. S. Multani, S. Pathak, P. Fedi, and K. S. Srivenugopal, "Human Dkk-1, a gene encoding a Wnt antagonist, responds to DNA damage and its overexpression sensitizes brain tumor cells to apoptosis following alkylation damage of DNA," Oncogene, vol. 21, no. 6, pp. 878-889, 2002.

[53] A. Y. Lee, B. He, L. You et al., "Dickkopf-1 antagonizes Wnt signaling independent of $\beta$-catenin in human mesothelioma," 
Biochemical and Biophysical Research Communications, vol. 323, no. 4, pp. 1246-1250, 2004.

[54] A. M. Mikheev, S. A. Mikheeva, B. Liu, P. Cohen, and H. Zarbl, "A functional genomics approach for the identification of putative tumor suppressor genes: dickkopf-1 as suppressor of HeLa cell transformation," Carcinogenesis, vol. 25, no. 1, pp. 4759, 2004.

[55] O. Aguilera, M. F. Fraga, E. Ballestar et al., "Epigenetic inactivation of the Wnt antagonist DICKKOPF-1 (DKK-1) gene in human colorectal cancer," Oncogene, vol. 25, no. 29, pp. 41164121, 2006.

[56] O. Aguilera, C. Peña, J. M. García et al., "The Wnt antagonist DICKKOPF-1 gene is induced by $1 \alpha, 25$-dihydroxyvitamin $\mathrm{D}_{3}$ associated to the differentiation of human colon cancer cells," Carcinogenesis, vol. 28, no. 9, pp. 1877-1884, 2007.

[57] W. H. Xu, Z. B. Liu, C. Yang, W. Qin, and Z. M. Shao, "Expression of Dickkopf-1 and beta-catenin related to the prognosis of breast cancer patients with triple negative phenotype," PLoS ONE, vol. 7, no. 5, Article ID e37624, 2012.

[58] H. Kim, E.-M. Seo, A. R. Sharma et al., "Regulation of Wnt signaling activity for growth suppression induced by quercetin in $4 \mathrm{~T} 1$ murine mammary cancer cells," International Journal of Oncology, vol. 43, no. 4, pp. 1319-1325, 2013.

[59] H. Hirata, Y. Hinoda, K. Nakajima et al., "Wnt antagonist DKK1 acts as a tumor suppressor gene that induces apoptosis and inhibits proliferation in human renal cell carcinoma," International Journal of Cancer, vol. 128, no. 8, pp. 1793-1803, 2011.

[60] S. H. Ralston, N. Galwey, I. Mackay et al., "Loci for regulation of bone mineral density in men and women identified by genome wide linkage scan: the FAMOS study," Human Molecular Genetics, vol. 14, no. 7, pp. 943-951, 2005.

[61] T. Koromila, P. Georgoulias, Z. Dailiana et al., "CER1 gene variations associated with bone mineral density, bone markers, and early menopause in postmenopausal women," Human Genomics, vol. 7, no. 1, article 21, 2013.

[62] J.-C. Hsieh, L. Kodjabachian, M. L. Rebbert et al., "A new secreted protein that binds to Wnt proteins and inhibits their activites," Nature, vol. 398, no. 6726, pp. 431-436, 1999.

[63] S. W. Cho, J.-Y. Yang, H. J. Sun et al., "Wnt inhibitory factor (WIF)-1 inhibits osteoblastic differentiation in mouse embryonic mesenchymal cells," Bone, vol. 44, no. 6, pp. 1069-1077, 2009.

[64] B. L. T. Vaes, K. J. Dechering, E. P. van Someren et al., "Microarray analysis reveals expression regulation of Wnt antagonists in differentiating osteoblasts," Bone, vol. 36, no. 5, pp. 803-811, 2005.

[65] K. Kawamoto, H. Hirata, N. Kikuno, Y. Tanaka, M. Nakagawa, and R. Dahiya, "DNA methylation and histone modifications cause silencing of Wnt antagonist gene in human renal cell carcinoma cell lines," International Journal of Cancer, vol. 123, no. 3, pp. 535-542, 2008.

[66] M. M. L. Baldewijns, I. J. H. van Vlodrop, L. J. Schouten, P. M. M. B. Soetekouw, A. P. de Bruïne, and M. van Engeland, "Genetics and epigenetics of renal cell cancer," Biochimica et Biophysica Acta, vol. 1785, no. 2, pp. 133-155, 2008.

[67] K. Kawakami, H. Hirata, S. Yamamura et al., "Functional significance of Wnt inhibitory factor-1 gene in kidney cancer," Cancer Research, vol. 69, no. 22, pp. 8603-8610, 2009.

[68] D. S. Yee, Y. Tang, X. Li et al., "The Wnt inhibitory factor 1 restoration in prostate cancer cells was associated with reduced tumor growth, decreased capacity of cell migration and invasion and a reversal of epithelial to mesenchymal transition," Molecular Cancer, vol. 9, article 162, 2010.

[69] C. Wissman, P. J. Wild, S. Kaiser et al., "WIF1, a component of the Wnt pathway, is down-regulated in prostate, breast, lung, and bladder cancer," Journal of Pathology, vol. 201, no. 2, pp. 204-212, 2003.

[70] S. Urakami, H. Shiina, H. Enokida et al., "Epigenetic inactivation of Wnt inhibitory factor-1 plays an important role in bladder cancer through aberrant canonical Wnt/beta-catenin signaling pathway," Clinical Cancer Research, vol. 12, no. 2, pp. 383-391, 2006.

[71] M. Kansara, M. Tsang, L. Kodjabachian et al., "Wnt inhibitory factor 1 is epigenetically silenced in human osteosarcoma, and targeted disruption accelerates osteosarcomagenesis in mice," The Journal of Clinical Investigation, vol. 119, no. 4, pp. 837-851, 2009.

[72] A. R. Sharma, C. Chakraborty, S.-S. Lee et al., "Computational biophysical, biochemical, and evolutionary signature of human R-spondin family proteins, the member of canonical Wnt/ $\beta$ catenin signaling pathway," BioMed Research International, vol. 2014, Article ID 974316, 22 pages, 2014.

[73] A. R. Sharma, B. S. Choi, J. M. Park et al., "Rspol promotes osteoblast differentiation via Wnt signaling pathway," Indian Journal of Biochemistry and Biophysics, vol. 50, no. 1, pp. 19-25, 2013.

[74] M. E. Binnerts, K.-A. Kim, J. M. Bright et al., "R-Spondin1 regulates Wnt signaling by inhibiting internalization of LRP6," Proceedings of the National Academy of Sciences of the United States of America, vol. 104, no. 37, pp. 14700-14705, 2007.

[75] K.-A. Kim, J. Zhao, S. Andarmani et al., "R-spondin proteins: a novel link to $\beta$-catenin activation," Cell Cycle, vol. 5, no. 1, pp. 23-26, 2006.

[76] A. Glinka, C. Dolde, N. Kirsch et al., "LGR4 and LGR5 are $\mathrm{R}$-spondin receptors mediating $\mathrm{Wnt} / \beta$-catenin and Wnt/PCP signalling," EMBO Reports, vol. 12, no. 10, pp. 1055-1061, 2011.

[77] W. de Lau, N. Barker, T. Y. Low et al., "Lgr5 homologues associate with Wnt receptors and mediate R-spondin signalling," Nature, vol. 476, no. 7360, pp. 293-297, 2011.

[78] K. S. Carmon, X. Gong, Q. Lin, A. Thomas, and Q. Liu, "Rspondins function as ligands of the orphan receptors LGR4 and LGR5 to regulate Wnt/beta-catenin signaling," Proceedings of the National Academy of Sciences of the United States of America, vol. 108, no. 28, pp. 11452-11457, 2011.

[79] J. Schuijers and H. Clevers, "Adult mammalian stem cells: the role of Wnt, Lgr5 and R-spondins," EMBO Journal, vol. 31, no. 12, pp. 2685-2696, 2012.

[80] W. B. M. de Lau, B. Snel, and H. C. Clevers, "The R-spondin protein family," Genome Biology, vol. 13, no. 3, article 242, 2012.

[81] J.-S. Nam, T. J. Turcotte, and J. K. Yoon, "Dynamic expression of R-spondin family genes in mouse development," Gene Expression Patterns, vol. 7, no. 3, pp. 306-312, 2007.

[82] K. D. Hankenson, M. T. Sweetwyne, H. Shitaye, and K. L. Posey, "Thrombospondins and novel TSR-containing proteins, R-spondins, regulate bone formation and remodeling," Current Osteoporosis Reports, vol. 8, no. 2, pp. 68-76, 2010.

[83] D. C. Blaydon, Y. Ishii, E. A. O’Toole et al., "The gene encoding R-spondin 4 (RSPO4), a secreted protein implicated in Wnt signaling, is mutated in inherited anonychia," Nature Genetics, vol. 38 , no. 11, pp. 1245-1247, 2006. 
[84] C. Bergmann, J. Senderek, D. Anhuf et al., "Mutations in the gene encoding the Wnt-signaling component R-spondin 4 (RSPO4) cause autosomal recessive anonychia," The American Journal of Human Genetics, vol. 79, no. 6, pp. 1105-1109, 2006.

[85] N. Wasif and W. Ahmad, "A novel nonsense mutation in RSPO4 gene underlies autosomal recessive congenital anonychia in a Pakistani family," Pediatric Dermatology, vol. 30, no. 1, pp. 139141, 2013.

[86] Y. Ishii, M. Wajid, H. Bazzi et al., "Mutations in R-spondin 4 (RSPO4) underlie inherited anonychia," Journal of Investigative Dermatology, vol. 128, no. 4, pp. 867-870, 2008.

[87] T. N. Khan, J. Klar, S. Nawaz et al., "Novel missense mutation in the RSPO4 gene in congenital hyponychia and evidence for a polymorphic initiation codon (p.M1I)," BMC Medical Genetics, vol. 13, article 120, 2012. 

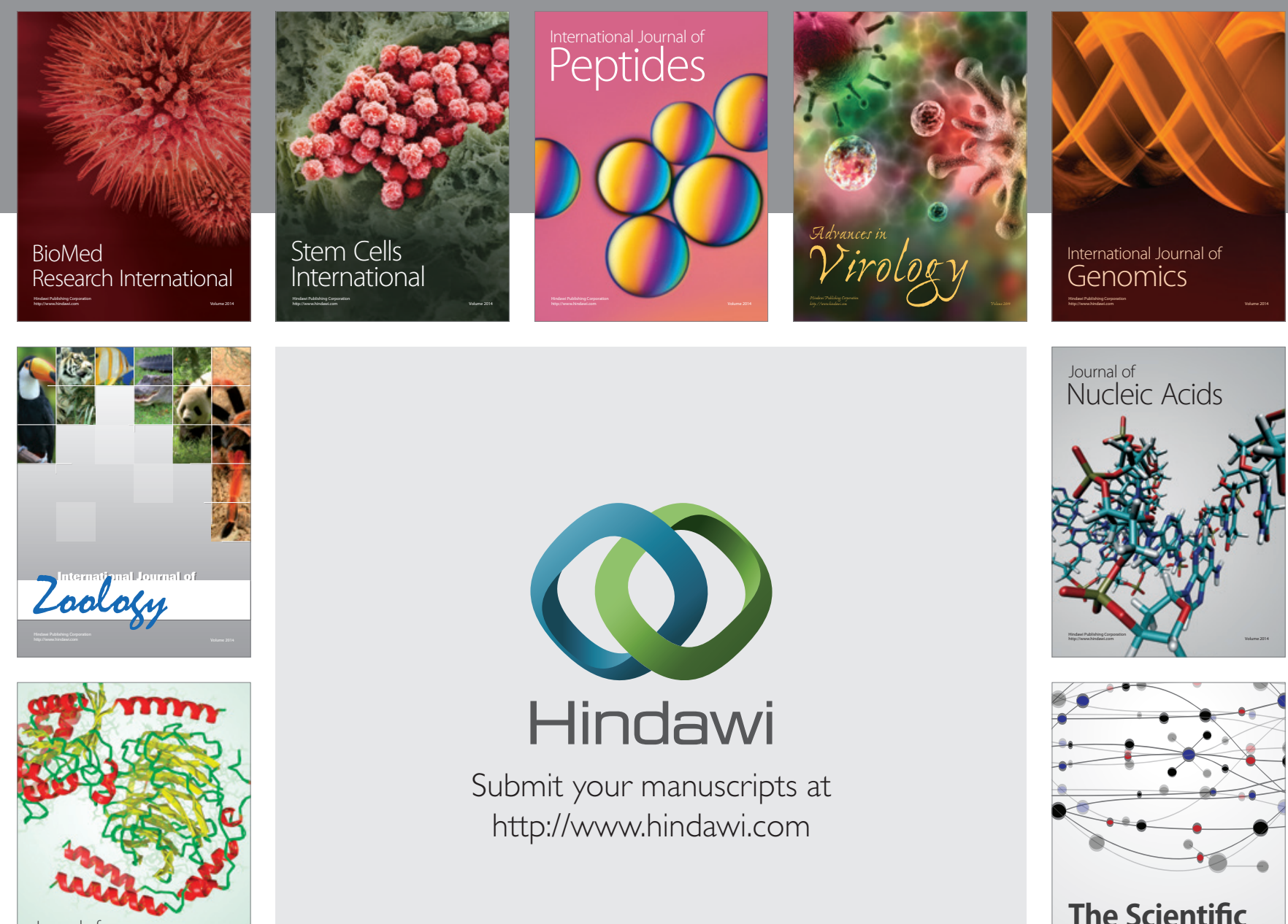

Submit your manuscripts at

http://www.hindawi.com

Journal of
Signal Transduction
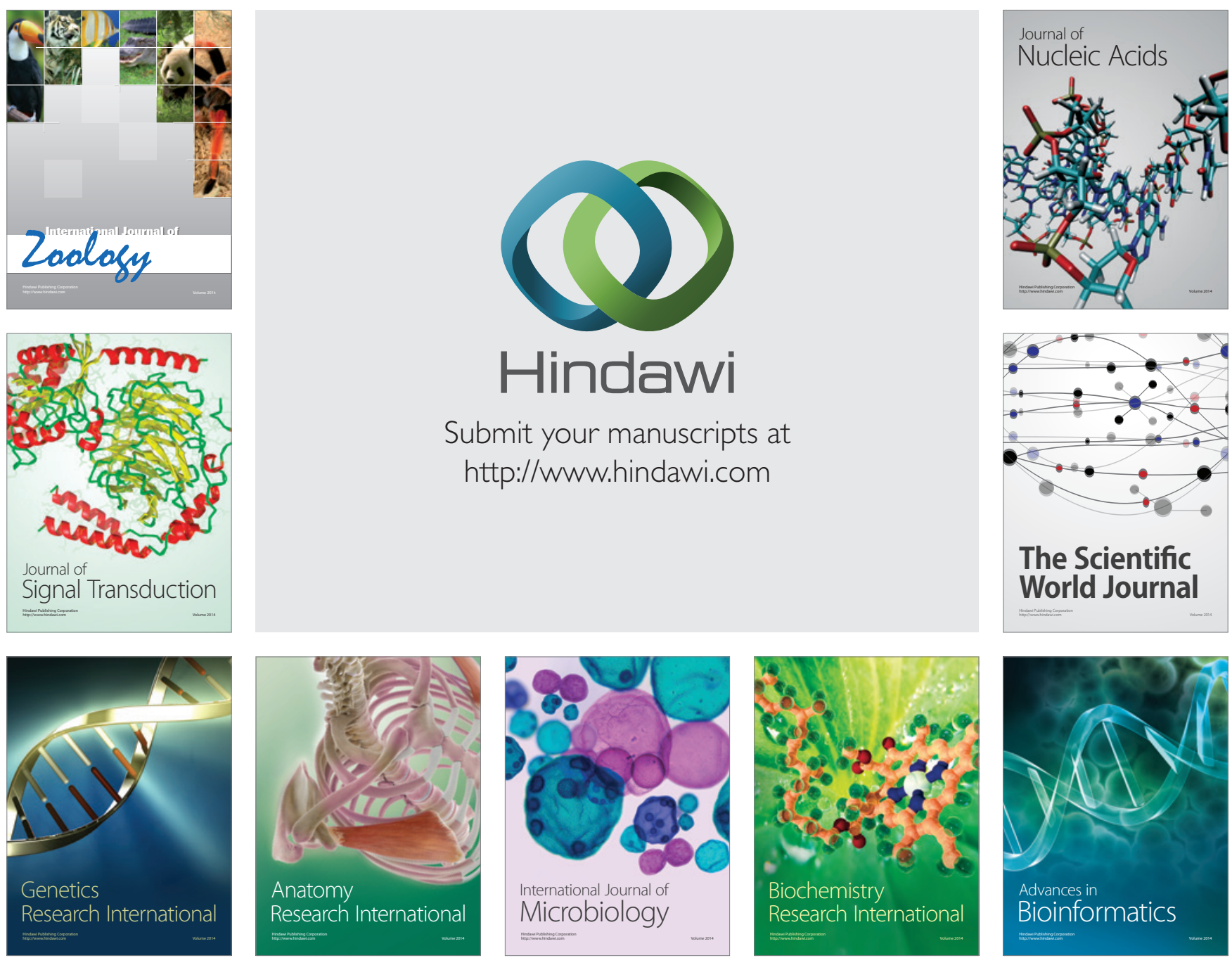

The Scientific World Journal
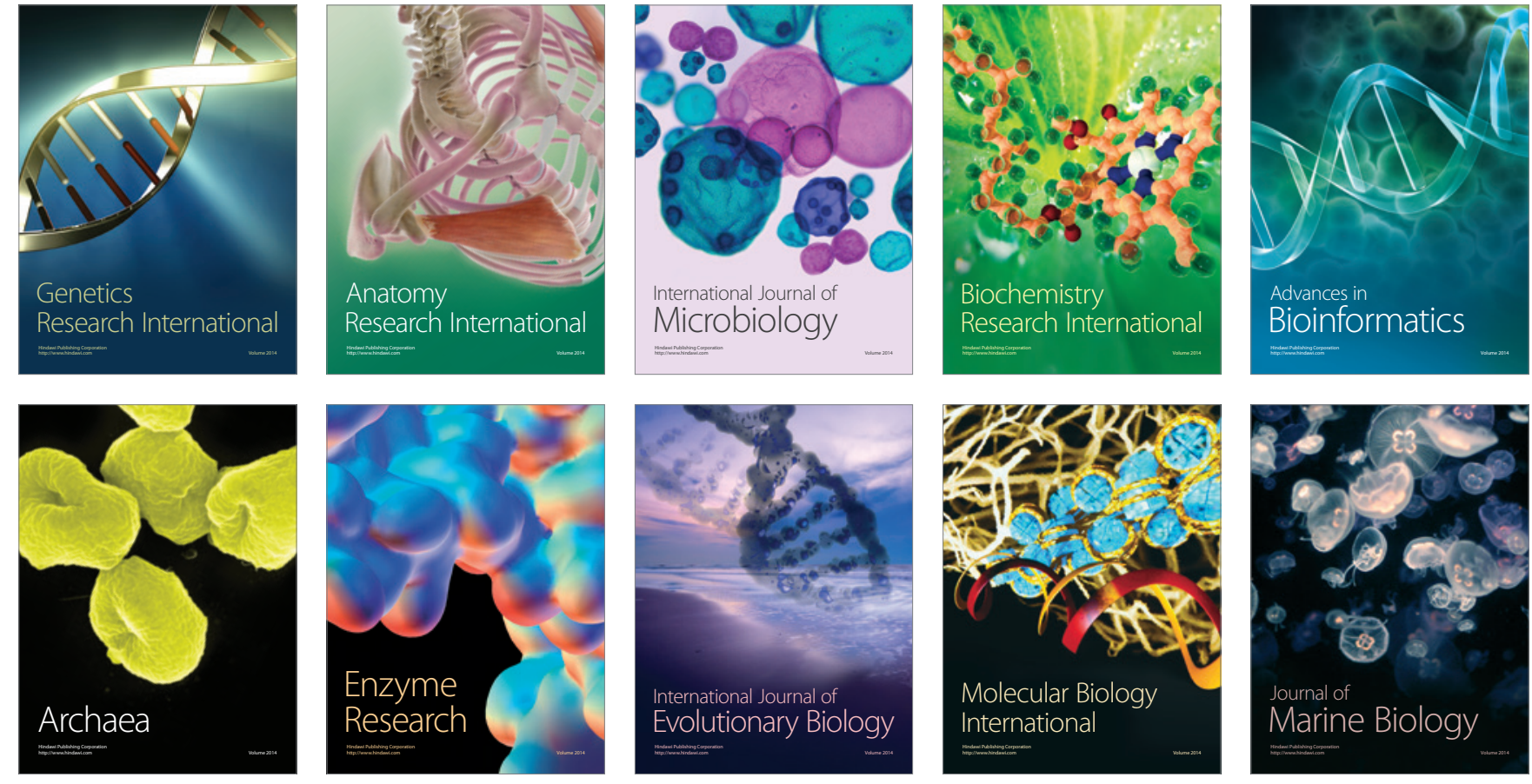